\title{
CPW-Fed UWB Slot Antenna with Triangular Tuning Stub
}

\author{
J. William and R. Nakkeeran
}

\begin{abstract}
Design and analysis of a new coplanar waveguide (CPW) fed ultra wideband (UWB) slot antenna is presented in this paper. The physical dimension of the antenna is around $28 \mathrm{~mm}$ (length) $\times 21 \mathrm{~mm}$ (width) $\times 1.6 \mathrm{~mm}$ (thickness) and fed by $50 \Omega$ coplanar waveguide. An extensive analysis of the proposed antenna in the frequency and time domains are presented. The antenna was fabricated using FR4 substrate and characterized by measuring return loss, radiation pattern $(6 \mathrm{GHz})$ and gain. The measured results are appreciably in good agreement with the simulation results. A better impedance bandwidth is obtained from 3.1 GHz to $11.4 \mathrm{GHz}$ that constitutes a fractional bandwidth of $114 \%$ with return loss less than or equal to $-10 \mathrm{~dB}$ $($ VSWR < 2). Time domain analysis of the antenna is also performed that witnessed the linear phase and less distortion. The simple configuration and low profile nature of the proposed antenna leads to easy fabrication that may be built for any wireless UWB device applications.
\end{abstract}

Index Terms - Coplanar Waveguide, slot antenna, standing wave ratio, time domain analysis, ultra wideband.

\section{INTRODUCTION}

UWB is a short range unlicensed wireless communication system which has a potential to offer a high capacity with low power than the current wireless systems for short range applications. In the year 2002, Federal Communications Commission (FCC) released the unlicensed UWB spectrum 3.1 GHz to $10.6 \mathrm{GHz}$ for the commercial purposes. After the release of Ultra Wideband (UWB) by the FCC, it receives much attention by the industries and academia due to its properties of low power consumption, support of high secured data rate and simple configuration [1]. With the rapid developments of such wireless systems, a lot of attention is being given for designing the UWB antennas, since they are the key elements to radiate and receive the UWB short puilse signals. To design an antenna to operate in the UWB band is quiet challenging one because it has to satisfy the requirements such as ultra wide impedance bandwidth, omni directional radiation pattern, constant gain, high radiation efficiency, constant group delay, low profile, compact and easy manufacturing [2]. Interestingly the planar slot antennas with CPW fed posses the above said features with simple structure, less radiation loss, less dispersion and easy integration of monolithic microwave integrated circuits (MMIC) [3]. Hence, the CPW fed planar slot antennas [4-6] are identified as the most promising design for wideband

J William is a research Scholar in the Department of ECE, Pondicherry Engineering College,Pondicherry. E-mail: wills.susan@ gmail.com.

R. Nakkeeran is with the Department of ECE, Pondicherry Engineering College,Pondicherry. E-mail: rnakeeran@pec.edu. wireless applications. In general, the wideband in CPW-fed slot antenna can be achieved by tuning their impedance value. Several impedance tuning techniques are reported in literature by varying the slot dimensions. For example, these have been carried out in various slot geometries like bow-tie slot [7], wide rectangular slot [8], circular slot [9] and hexagonal slot [10]. The impedance tuning can also be performed by using coupling techniques like inductively and capacitively coupled slots [11], dielectric resonator coupling [12] and other techniques such as using photonic band gap (PGB) [13]. Even though large impedance bandwidth could be obtained by using these techniques, they are quite complicated. In planar slot antennas two parameters affect the impedance bandwidth of the antenna, the slot width and the feed structure. The wider slot gives more bandwidth and the optimum feed structure gives the good impedance matching [14]. The proposed antenna in this paper is designed with a compact rectangular slot and a triangular feeding structure at the anterior portion of the feed. The antenna is only one of its kinds in structure, small in size and simple design due to less number of design parameters compared with the existing ultra wideband antennas in the literature [15-18]. The pattern obtained from the simulation is almost stable across the matching band with an average gain of $4 \mathrm{dBi}$. The simulation software used for this analysis is IE3D [19]. The details of the proposed design and its experimental result is presented and discussed in the following Sections. The different sections of this paper are organized as follows: Section II brings out the antenna design and geometry of the antenna. In Section III simulation results and analysis are presented. Obtained experimental results are given in Section IV. Section V concludes the paper.

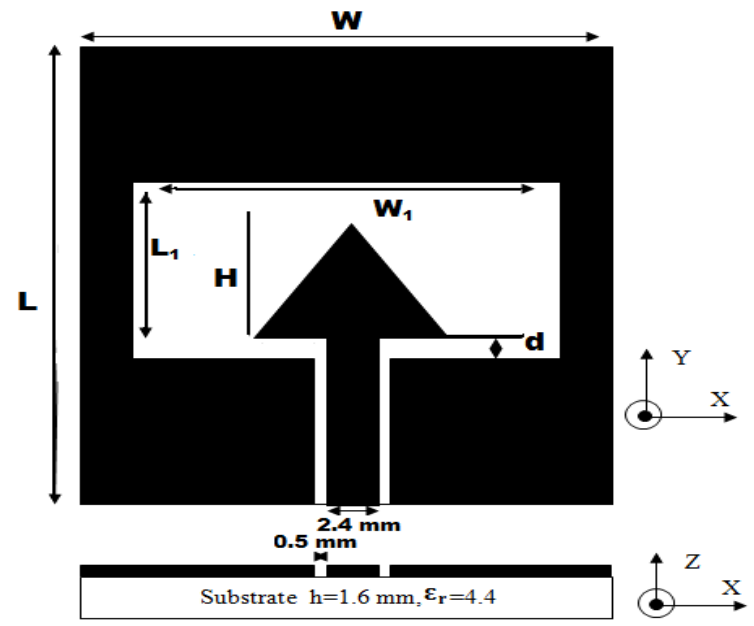

Fig. 1 Geometry of the proposed CPW-fed rectangular slot antenna 


\section{ANTENNA Design AND GeOMETRY}

The structure of the antenna is shown in Fig 1. The antenna consists of rectangular slot with width ' $\mathrm{W}_{1}$ ' and length ' $\mathrm{L}_{1}$ '. The tuning stub comprises a triangular patch with height ' $H$ '. The distance between the tuning stub and feed line is ' $d$ ', ' $W$ ' and ' $L$ ' are the overall width and length of the antenna respectively. In this study, the dielectric substance (FR4) with thickness of $1.6 \mathrm{~mm}$ with relative permittivity of 4.4 is chosen as substrate to facilitate printed circuit board integration. The CPW feed is designed for $50 \Omega$ characteristic impedance with fixed $2.4 \mathrm{~mm}$ feed line width and $0.5 \mathrm{~mm}$ ground gap. The designed values of the antenna are optimized with IE3D tool. The optimization was performed for the best impedance bandwidth. To improve the bandwidth of the system the proposed structure is a slight dimensional modification of our previous work [20] to cover the entire UWB range. The proposed antenna produces wide bandwidth with omni-directional radiation pattern. The wide bandwidth and wide impedance matching with reduced size of the antenna is achieved due to resultant of different magnetic currents of the structure.

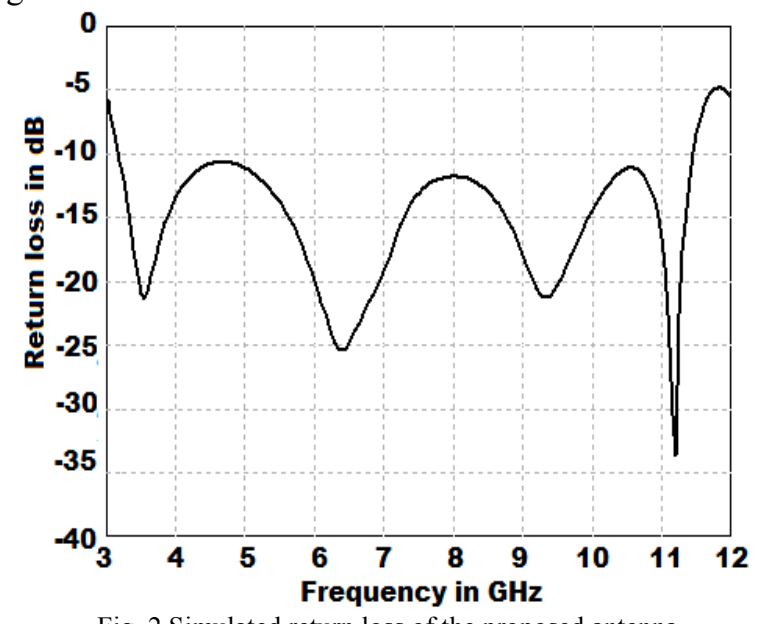

Fig. 2 Simulated return loss of the proposed antenna

\section{Simulated Results And AnAlysis}

The analysis and performance of the proposed antenna is explored by using IE3D for the better impedance matching. The analysis of the antenna carried out by varying one parameter and keeping other parameters constant. The optimal parameter values of the antenna are listed in the Table 1.

TABLE I. OPTIMAL PARAMETER VALUES OF THE ANTENNA

\begin{tabular}{|c|c|c|}
\hline Parameter & Description & Optimal Value \\
\hline $\mathrm{L}$ & Length of the antenna & $28 \mathrm{~mm}$ \\
\hline $\mathrm{W}$ & Width of the antenna & $21 \mathrm{~mm}$ \\
\hline $\mathrm{L}_{1}$ & Length of the slot & $15 \mathrm{~mm}$ \\
\hline $\mathrm{W}_{1}$ & Width of the slot & $16.8 \mathrm{~mm}$ \\
\hline $\mathrm{d}$ & Feed gap distance & $1.6 \mathrm{~mm}$ \\
\hline $\mathrm{H}$ & Height of the patch & $9.3 \mathrm{~mm}$ \\
\hline
\end{tabular}

The simulated return loss of the proposed antenna is shown in Fig. 2, which clearly indicates that the impedance bandwidth of the antenna is $8.3 \mathrm{GHz}(3.1 \mathrm{GHz}-11.4 \mathrm{GHz})$ for VSWR less than 2. The ultra wideband is due to multiple resonances introduced by the combination of the rectangular slot and the tuning stub. The resonant frequency and bandwidth are controlled by the size of the rectangular slot, antenna and tuning stub. Proper geometrical selection of the antenna parameters result in variation of field distribution, which in turn affects the characteristics of the proposed antenna.

\section{A. Effect of Parameters' $W_{l}$ ' and ' $L_{l}$ '}

For the fixed values of $\mathrm{L}$ and $\mathrm{W}$, the length and width of the rectangular slot ' $\mathrm{L} 1$ ' and ' $\mathrm{W} 1$ ' are varied and the simulation results are displayed in Fig. 3. If the value of ' $L 1$ ' is increased, the impedance matching is reduced over the entire bandwidth. If the value of ' $\mathrm{L} 1$ ' is decreased the impedance bandwidth of the antenna is reduced. Similarly by varying the values of 'W1' significant variations in the response are noticed, which clearly point out that these two parameters affect the bandwidth and impedance matching of the antenna. It is found that the optimal size of the slot is $15 \mathrm{~mm} \times 16.8 \mathrm{~mm}$.

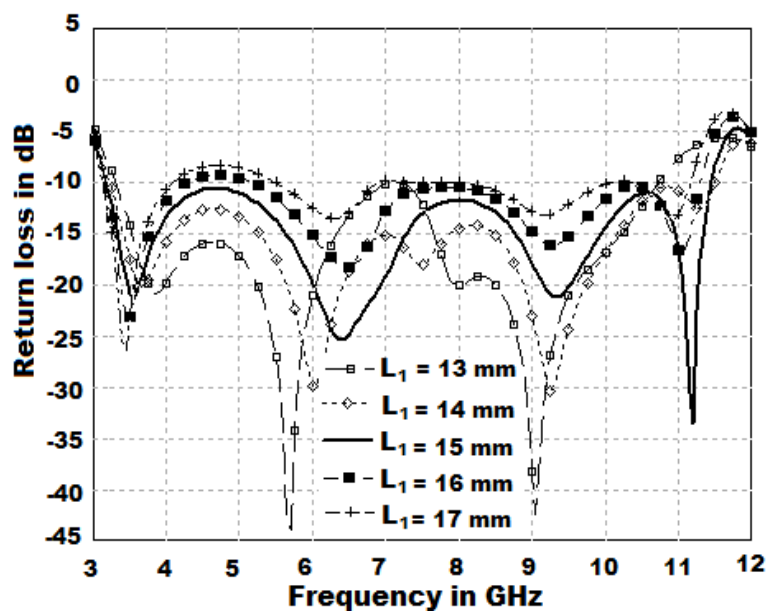

(a)

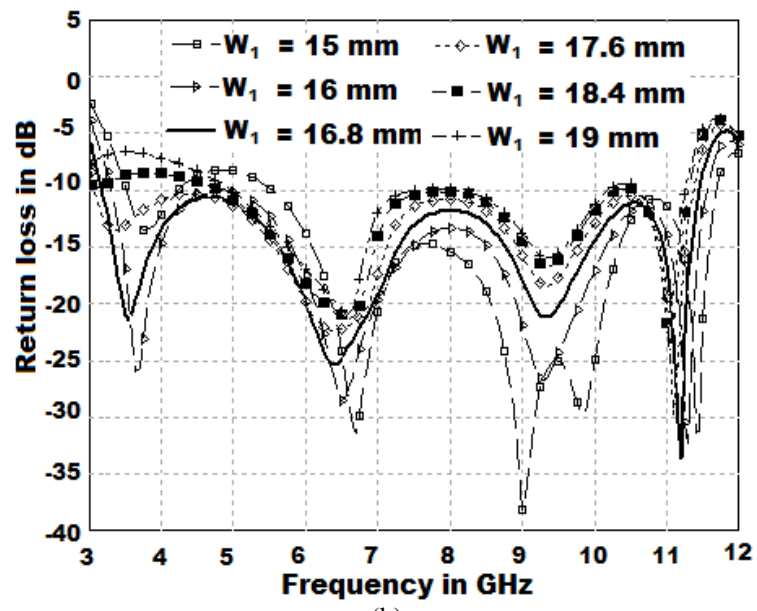

(b)

Fig. 3. Simulated return loss curves for a) different lengths ' $L_{1}$ ' b) different widths ' $\mathrm{W}_{1}$ '

\section{B. Effect of Feed Gap Distance}

For fixed values of $\mathrm{W}_{1}, \mathrm{~L}_{1}$ and $\mathrm{H}$, Fig. 4 displays the simulated return loss for different feed gap distances $(\mathrm{d}=1.2,1.4,1.6,1.8$ and $2 \mathrm{~mm})$. The responses clearly illustrate that as the feed width increases, the impedance matching becomes poorer at lower frequencies and slight shift in resonant frequency takes place. If the feed gap value is decreased, the response at the higher frequencies becomes poorer. Hence, it is concluded that the feed width is one of the parameter that affects the impedance matching. It is also found that the optimal value for this case is $1.6 \mathrm{~mm}$. 


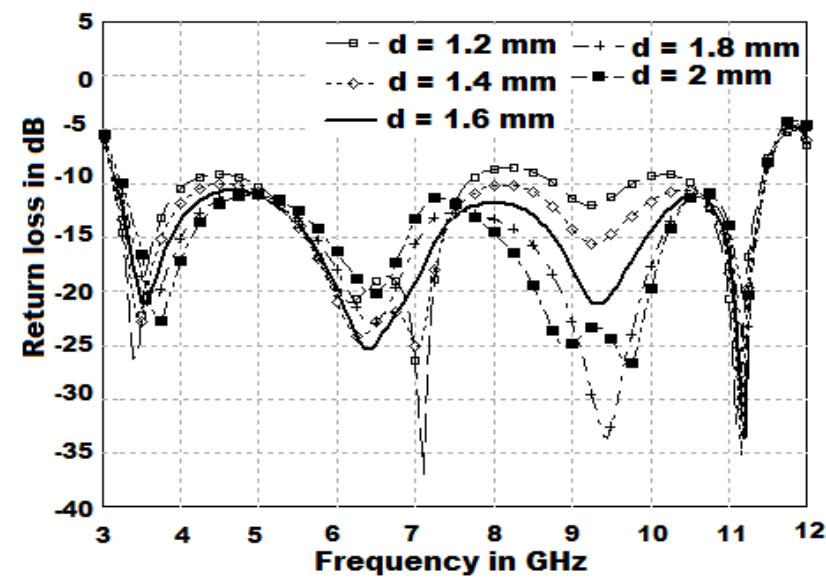

Fig. 4 Return losses for different feed gaps

\section{Effect of Triangular Patch Heights}

The effect of bandwidth for different heights ' $\mathrm{H}$ ' of the triangular patch is depicted in Fig. 5, which discloses the profiles of the impedance matching. Variation in the values of ' $\mathrm{H}$ ' influences variation in the response at lower frequencies and the optimal value for this case is $9.3 \mathrm{~mm}$.

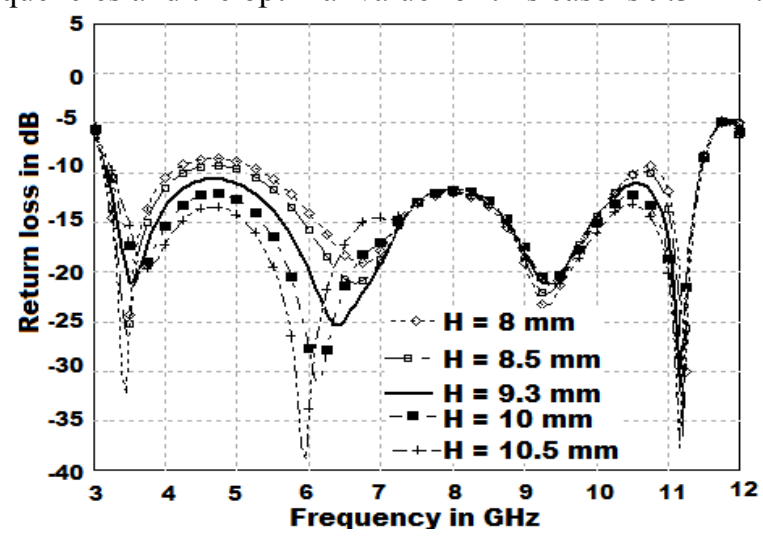

Fig. 5 Return loss curves for different heights

\section{Radiation pattern}

The simulated radiation patterns of the $\mathrm{E}$ plane and $\mathrm{H}$ plane are obtained at 4, 7 and $11 \mathrm{GHz}$ are shown in Fig. 6.

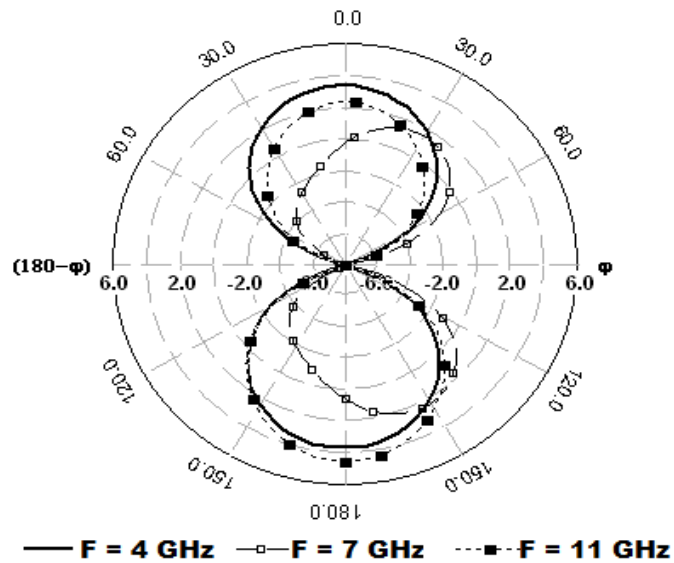

(a)

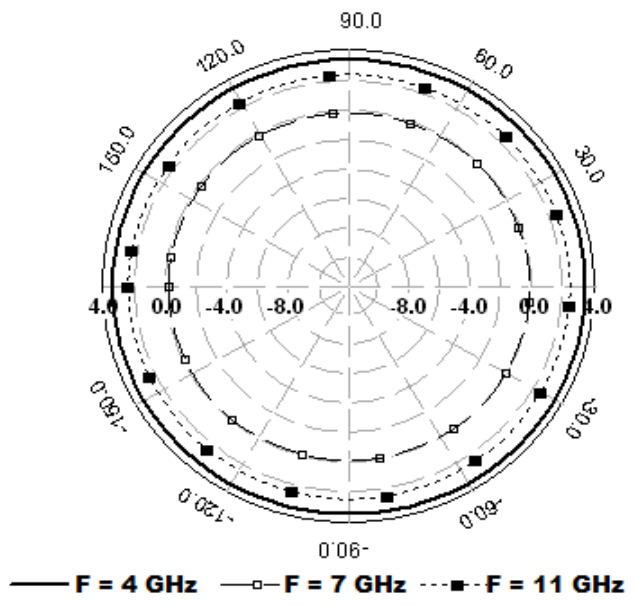

(b)

Fig. 6 Radiation pattern of the proposed antenna at 4, 7 and $11 \mathrm{GHz}$ $\begin{array}{ll}\text { a) E-Plane (yz-plane) } & \text { b) H-Plane (xz-plane) }\end{array}$

It is noticed that in $\mathrm{H}$ plane, the radiation pattern is omni directional and in $\mathrm{E}$ plane the radiation pattern is bidirectional. As the frequency increases, there is a decrease in the gain due to low profile of the proposed antenna structure. Proper geometrical selection of the antenna results variations in field distribution, which in turn affects the characteristics of the proposed antenna.

\section{EXPERIMENTAL RESUlTS AND DisCUSSIONS}

\section{A. Frequency domain analysis}

The prototype of the proposed antenna was fabricated for different parameters with their optimal values and tested that is depicted in Fig.7. All the measurements are carried out using Vector Network Analyzer (VNA) Agilent HP 8250. The return loss is measured and plotted to indicate that it covers wide bandwidth of $7.7 \mathrm{GHz}(3.1 \mathrm{GHz}-10.8 \mathrm{GHz})$.
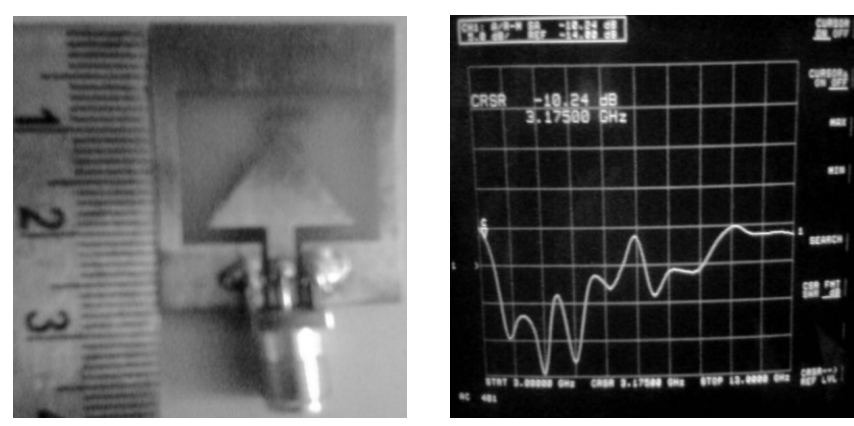

Fig. 7 Fabricated antenna and its measured return loss.

The simulated and measured return loss of the proposed antenna is illustrated in Fig.8. The discrepancy between the measured and the simulated one is due to the effect of improper soldering of SMA connector or fabrication tolerance. The simulation results were obtained by assuming coplanar input port, whereas practically SMA connector was used, the imp effect transition between SMA feed to coplanar may introduce losses [22] and shift in the frequency. However, the measured bandwidth is relatively equal to the simulated impedance bandwidth, 8.3 GHz (3.1- 11.4 GHz). Antenna radiation patterns at frequency $6 \mathrm{GHz}$ for the E-plane and H-plane are measured and plotted in along with simulated as shown in Fig. 9, which is omni directional in the 
H-plane and bidirectional in the E-plane. The comparison of the measured antenna gain with the simulated one is shown in Fig. 10 which also shows reasonable agreement and nearly stable throughout the entire band.

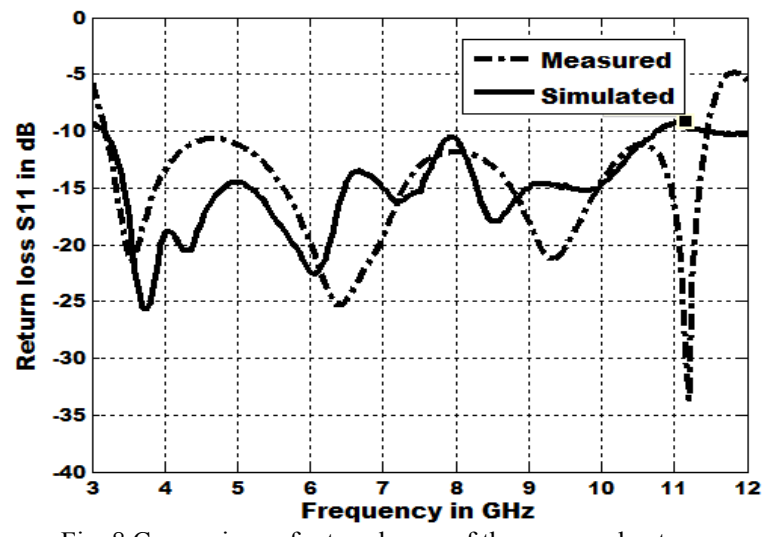

Fig. 8 Comparison of return losses of the proposed antenna

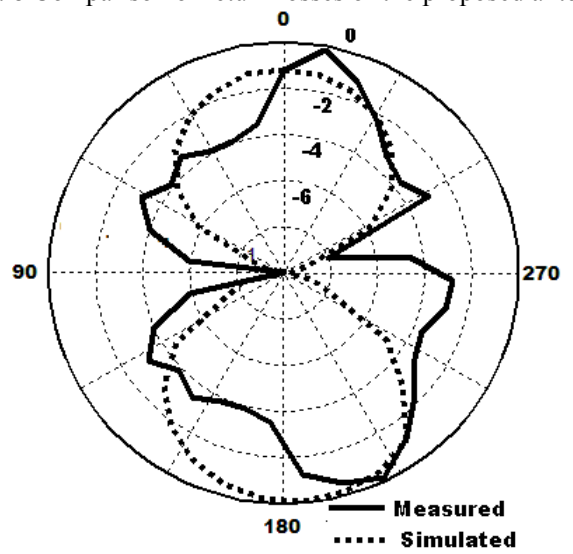

(a)

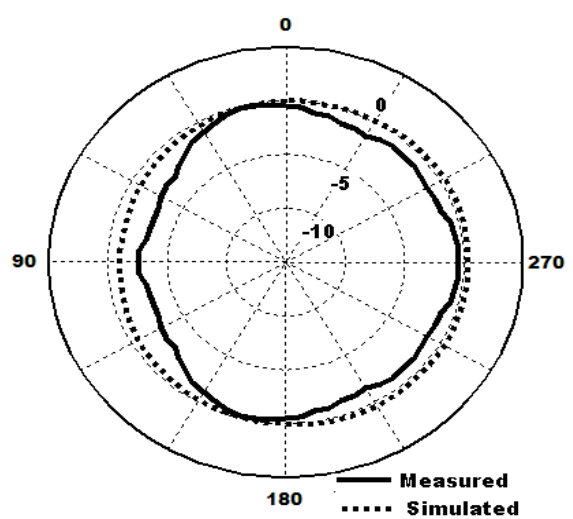

(b)

Fig. 9 Comparison of radiation pattern at $6.5 \mathrm{GHz}$ a) E-Plane b) H-Plane

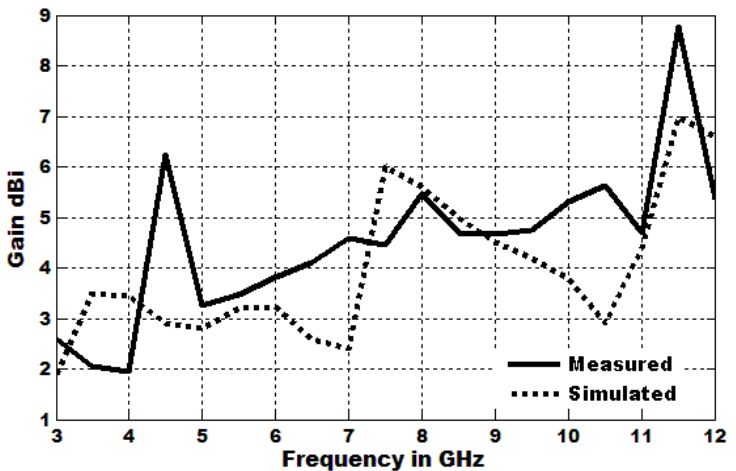

Fig. 10 Gain comparison

\section{B. Time domain analysis}

In ultra wideband systems, the information is transmitted using short pulses. Hence, it is important to study the temporal behavior of the transmitted pulse. The communication system for UWB pulse transmission must provide as minimum as possible distortion, spreading and disturbance. The channel is assumed to be linear time invariant (LTI) system to verify the capability of the proposed antenna for transmission and reception of these narrow pulses. The group delay is measured by placing two identical antennas at a distance of $75 \mathrm{~mm}$ which is greater than the far field distance of the antenna. The comparison of the measured and simulated group delay is shown in Fig.11, which illustrates that the group delay variation is within $2 \mathrm{~ns}$ which is acceptable one. The transient response of the antenna performed from the transfer function of the system is computed using measured value of ' $\mathrm{S}_{21}$ ' parameter [22].

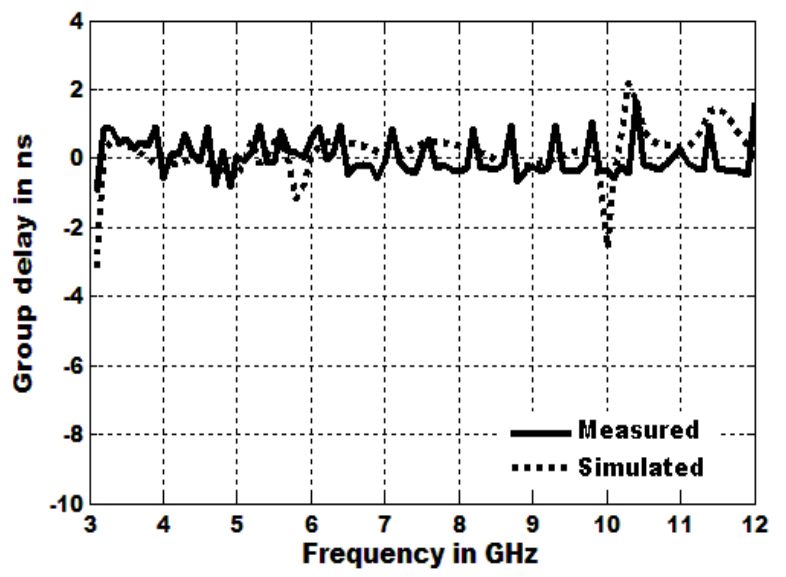

Fig. 11 Group delay performance

The received output pulse is obtained by taking the Inverse Fourier Transform (IFT) of the product of transfer function and spectrum of the test input pulse. The cosine modulated Gaussian pulse is considered for this analysis with centre frequency of $6.85 \mathrm{GHz}$ and pulse width of 220 picoseconds, whose spectrum is shown in Fig. 12. It satisfies the requirement of FCC mask for UWB indoor emission. The comparison of transmitted input pulse and received output pulse of the antenna is shown in Fig.13, which ensures the distortion less pulse transmission and also guarantees that the designed antenna is capable of transmitting and receiving short pulses. The ringing effect in the waveform may be due to the transmission properties of the system.

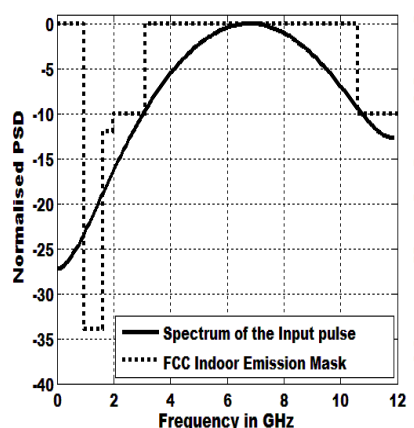

(a)

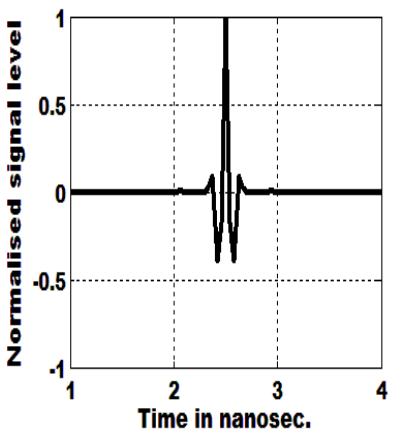

(b)
Fig. 12 a) Spectrum of the test input pulse with FCC mask b) input pulse in time domain 


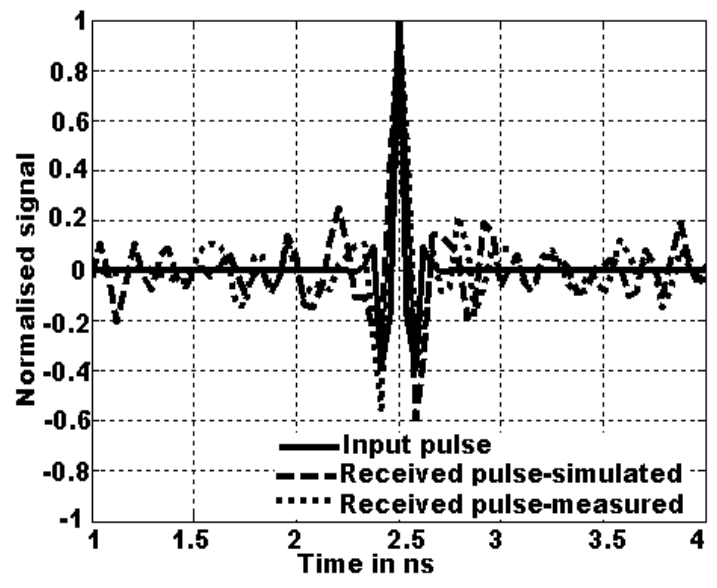

Fig. 13 Comparison of input pulse with received output pulse

\section{CONCLUSION}

In this paper, a simple antenna structure has been proposed with minimal antenna size and better impedance matching. To enhance the coupling between the slot and feed, a triangular tuning stub is introduced at the anterior portion of the slot. With the above structural features the overall dimension of the proposed antenna configuration comes around $28 \mathrm{~mm} \times 21 \mathrm{~mm} \times 1.6 \mathrm{~mm}$. A fractional bandwidth of $114 \%$ over the frequency range of $3.1 \mathrm{GHz}$ to $11.4 \mathrm{GHz}$ is achieved through the proposed structure. The computed time domain analysis of the designed antenna ensures the capability of the antenna working in the UWB environment. Hence, this type of antenna is suitable for UWB indoor applications.

\section{REFERENCES}

[1] FCC NEWS(FCC 02-48), Feb. 14,2002. FCC News release

[2] M. Ghavami, L.B. Michael and R. Kohno, Ultra Wideband Signals and Systems in Communication Engineering, John Wiley and sons. Inc., NY, USA, 2004.

[3] Rainee N.Simons, Coplanar waveguide Circuits Components and Systems, John Wiley and sons. Inc., NY, USA, 2001.

[4] J.Y. Chiou, J.Y. Sze and K.L. Wong, "A broad-band CPW-fed striploaded square slot antenna," IEEE Trans. Antennas and Propag., Vol. 51, No.4,April 2003, pp. 791-721.

[5] H.D. Chen, "Broadband CPW-fed square slot antenna with a widened tuning stub," IEEE Trans. Antennas and Propag., Vol. 51, No 8, Aug 2003, pp. 1982-1986.

[6] S.M.Deng and H.H.Kan, "Analysis of CPW-fed triangle patch antennas," IEEE Trans. Antennas and Propag., Vol.3, 2001, pp. 398-401.

[7] L. Marantis and Paul Brennan, "A CPW-Fed Bow-Tie Slot Antenna With Tuning Stub,” Proc. Of Loughborough Antennas \& Propagation Conference, Mar 2008, pp 389-393.

[8] W. Q. Chen, G. F. Ding et.al, "Design and Simulation of Broadband Unidirectional CPW-Fed Rectangular Slot Antennas,'IEEE International Symposium on Microwave, Antenna, Propagation and EMC Technologies For Wireless Communications, 2007, pp. 632-635.

[9] E. A. Soliman, S. Brebels, E. Beyne, and G. A. E. Vandenbosch, "CPW-fed cusp antenna," Microwave Opt. Technol. Lett., Vol. 22, Aug. 1999, pp.288-290.

[10] Kraisorn Sari-kha, Vech Vivek, and Prayoot Akkaraekthalin , "A Broadband CPW-fed Equilateral Hexagonal Slot Antenna,” Proc. Of IEEE International Conference on Computer Systems and Information Technology, Sept. 2006, pp.783-786.

[11] L.Giauffret, J. Laheurte, and A. Papiernik, "Study of various shapes of the coupling slot in CPW-fed Microstrip antennas," IEEE Trans. Antennas Propag., Vol. 45, April 1997, pp.642-647.

[12] M.S. Al Salameh, Y.M.M Antar, and G. Seguin, "Coplanar waveguidefed slot coupled rectangular dielectric resonator antenna," IEEE Trans. Antennas Propag., Vol.50, No.10, Oct 2002, pp.1415-1419.
[13] L.T. Wang, X.C. Lin, and J.S. Sun, "The broadband loop slot antenna with photonic bandgap," Proc. Int. Conference on Antennas and Propagation, Vol.2, 2003, pp.470-472.

[14] Shun-Yun Lin et al, "A Novel Compact Slot Antenna for Ultra-Wideband Communications," IEEE Antennas and Propagation International Symposium, June 2007, pp. 5123-5126.

[15] R.Chair, A.A.Kishk and K.F.Lee,"Ultrawide band Coplanar Waveguide-Fed Rectangular Slot antenna," IEEE Antennas Wirel. Propag. Lett., Vol.3, 2004, pp.227- 229.

[16] Yi-Cheng Lin and Kuan-Jung Hung, "Compact Ultrawideband Rectangular Aperture Antenna and Band-Notched Designs," IEEE Trans. Antennas Propag., Vol.54, No.11, Nov.2006, pp.3075-3081.

[17] X.Chen, W.Zhang, R.Ma, J.Zhang and J.Gao, "Ultra-wideband CPW-fed antenna with round corner rectangular slot and partial circular patch," IET Microwave Antennas and Propagation, Vol.1, No.4, Aug. 2007, pp.847-851.

[18] Z.Li, C.X. Zhang et al, "Designs on CPW-Fed Aperture Antenna for Ultra-wideband Application,'Journal of Progress in Electromagnetic Research, Vol.2,,2008, pp 1-6.

[19] IE3D 14, Zeland Software, Ins., Fremont, USA.

[20] J. William and R. Nakkeeran, "A CPW-fed wideband slot antenna with triangular patch," Proc. of IEEE Intl. Conference on Computing, Communication and Networking, Dec. 2008.

[21] Kuang - ping ma, Yongxi Qian and Tatsuo Itoh, "Analysis and applications of a New CPW- slot line Transition," IEEE Transactions on Microwave theory and Techniques, Vol. 47, April 1999, pp. 426-432.

[22] Stanislas Licul and William A Davis, "Ultra-wideband(UWB) antenna measurements using vector Network analyzer," IEEE Antennas and Propagation International Symposium, June 2004, pp. 1319-1322.

J.William was born in India. He received the B.E. degree in Electronics and Communication from Bharathidasan University, Tamilnadu, India, and the M.Tech.degree in Communication Systems from National Institute of Technology(N.I.T), Trichy,India, in 1991 and 2006 respectively. He is currently working towards the Ph.D. degree at Pondicherry Engineering College,Pondicherry, India. He is a life member of ISTE, IE(I) and EurAAP. His current research interest is in the area of coplanar antennas and printed slot antennas for UWB.

Dr. R. Nakkeeran Received BSc. Degree in Science and B.E degree in Electronics and Communication Engineering from the Madras University in 1987 and 1991 respectively and M.E degree in Electronics and Communication Engineering (diversification in Optical Communication) from the Anna University in 1995. He received Ph.D degree from Pondicherry University in 2004. Since 1991, he has been working in the teaching profession. Presently, he is Associate Professor in Pondicherry Engineering College. He is life member of IETE, ISTE, OSI and IE(I). Also he is member of OSA, SPIE and IEEE. He has published seventy five papers in National and International Conference Proceedings and Journals. He has co-authored a book, published PHI. His areas of interest are Optical Communication, Networks, Antennas, Electromagnetic Fields and Wireless Communication. 